\title{
DISTRIBUIÇÃO DO SISTEMA RADICULAR DE CITROS EM UMA TOPOSSEQÜÊNCIA DE SOLOS DE TABULEIRO COSTEIRO DO ESTADO DA BAHIA ${ }^{(1)}$
}

\author{
Luciano da Silva Souza ${ }^{(2)}$, Laercio Duarte Souza ${ }^{(2)}$, Arlicélio de \\ Queiroz Paiva $^{(3)}$, Anderson Clécio Vieira Rodrigues ${ }^{(4)} \&$ Luciano \\ da Silva Ribeiro ${ }^{(5)}$
}

\begin{abstract}
RESUMO
O aprofundamento do sistema radicular dos citros é importante para aumentar a produtividade e a longevidade dessa cultura, principalmente em solos que apresentam horizontes coesos subsuperficiais. Assim, o objetivo deste trabalho foi avaliar a distribuição das raízes da laranjeira 'Hamlin' enxertada em limoeiro 'Cravo', com 15 anos de idade, em uma toposseqüência de tabuleiro de SapeaçuBA, composta por Latossolo Amarelo argissólico (LAx) e Argissolo Amarelo (PAx), ambos coesos, e Argissolo Acinzentado (PAC), não coeso. Em 2001, retiraram-se amostras de raízes em uma planta no LAx e no PAx e em duas no PAC, em quatro horizontes, em quatro pontos na linha e em cinco na entrelinha, distanciados por $0,50 \mathrm{~m}$, usando-se um cilindro de aço de $1,20 \mathrm{~m}$ de comprimento e 0,085 $\mathrm{m}$ de diâmetro. As raízes foram digitalizadas em escaner e processadas no aplicativo GSRoot. As raízes da laranjeira 'Hamlin' enxertada em limoeiro 'Cravo' apresentaram grande sensibilidade à coesão, sendo a densidade de raízes 3,4 a 4,1 vezes maior no solo PAC, não coeso. A densidade das raízes encontradas nos horizontes superficiais do LAx e do PAx foi próxima daquela do horizonte mais profundo do PAC. A profundidade efetiva do sistema radicular, até onde se encontraram 80 \% das raízes, foi maior no PAC não coeso, e a distância efetiva do sistema radicular, até onde se encontraram 80 \% das raízes a partir do tronco, foi maior no PAx coeso, que foi o solo que apresentou a menor profundidade efetiva
\end{abstract}

\footnotetext{
(1) Recebido para publicação em julho de 2006 e aprovado em novembro de 2007.

(2) Pesquisador da Embrapa Mandioca e Fruticultura Tropical. Caixa Postal 7, CEP 44380-000 Cruz das Almas (BA). E-mails: lsouza@cnpmf.embrapa.br; laercio@cnpmf.embrapa.br

(3) Professor do Departamento de Ciências Agrárias e Ambientais, Universidade Estadual de Santa Cruz - UESC. Rod. IlhéusItabuna, Km 16, CEP 45650-000 Ilhéus (BA). E-mail: arli@uesc.br

(4) Engenheiro-Agrônomo, profissional liberal. Caixa Postal 7, CEP 44380-000 Cruz das Almas (BA).

(5) Engenheiro-Agrônomo do Banco do Nordeste do Brasil. Rua 18 de Maio 186, Itaberaba (BA). E-mail: lucianosr@bnb.gov.br
} 
das raízes. Nos três solos, houve predominância de raízes com diâmetros $<1 \mathrm{~mm}$, seguidas daquelas com diâmetros entre 1 e 2 e $>2 \mathrm{~mm}$.

Termos para indexação: coesão, Latossolo Amarelo argissólico, Argissolo Amarelo, Argissolo Acinzentado.

\title{
SUMMARY: CITRUS ROOT SYSTEM DISTRIBUTION INA COASTAL TABLE LAND SOIL TOPOSEQUENCE OF THE STATE OF BAHIA, BRAZIL
}

\begin{abstract}
The deepening of citrus root system is important to increase crop productivity and longevity, especially in soils with subsurface cohesive horizons. The objective of this study was to evaluate the root distribution of 'Hamlim' sweet orange grafted onto Rangpur lime. The 15 year-old plants were located in a coastal plain soil toposequence in Sapeaçu county, Bahia, Brazil. The soils were an argisolic Yellow Latosol (LAx; Oxisol) and a Yellow Argisol (PAx; Ultisol), both cohesive, and a non-cohesive Gray Argisol (PAC; Ultisol). In 2001, root samples were collected from one plant in the LAx and from one plant in the PAx, and from two plants in the PAC. Samples were collected in four horizons, four points in the row and five points in the inter-rows, spaced at $0.50 \mathrm{~m}$, using a steel cylinder with a length of $1.20 \mathrm{~m}$ and diameter of $0.085 \mathrm{~m}$. The collected roots were scanned and processed using the GSRoot software. 'Hamlim' sweet orange roots grafted onto Rangpur lime were highly sensitive to soil cohesion. The root density in the PAC was 3.4 to 4.1 times higher than in the LAx and PAx, respectively. Root density in the LAx and PAx surface horizons was close to that in the deepest horizon of the PAC. The effective depth root system, where $80 \%$ of the roots can be found, was higher in the PAC, non-cohesive soil, while the effective distance, where $80 \%$ of the roots measured from the tree trunk can be found, was higher in the PAx, cohesive soil. In the PAx the effective depth of the root system was the smallest. In the three soils the roots with diameter $<1 \mathrm{~mm}$ were predominant, followed by those with diameter between 1 and 2 and $>2 \mathrm{~mm}$.
\end{abstract}

Index terms: soil cohesion, argisolic Yellow Latosol, Yellow Argisol, Gray Argisol.

\section{INTRODUÇÃO}

Os solos dos Tabuleiros Costeiros são formações terciárias que aparecem desde o Amapá até o Rio de Janeiro, ocupando cerca de 10 milhões de hectares apenas no litoral do Nordeste. A região de ocorrência dos tabuleiros apresenta significativa importância econômica e social, devido à alta densidade demográfica e ao enorme potencial como produtora de alimentos, principalmente frutas. A citricultura da Bahia e de Sergipe, representando cerca de 100.000 ha, está localizada nesse ecossistema. Embora os solos sejam considerados profundos, horizontes coesos, com estrutura maciça e consistência dura a extremamente dura quando secos, reduzem a profundidade efetiva, prejudicando a dinâmica da água no perfil e, principalmente, o aprofundamento do sistema radicular das culturas. Souza (1997) afirma que uma das medidas para aumentar a produtividade e a longevidade das culturas é a melhoria do crescimento radicular em profundidade, o que aumentaria a superfície de absorção de nutrientes e, principalmente, de água pelas plantas, minimizando assim os efeitos das freqüentes estiagens verificadas em grande parte da região de tais solos.
O desenvolvimento radicular em profundidade nos solos de tabuleiro é pouco expressivo; nos horizontes inferiores as raízes tendem a se desenvolver apenas nas fraturas (Demattê et al., 1996). Rezende et al. (2002) registram o desenvolvimento prejudicado do sistema radicular de citros nos solos coesos dos Tabuleiros Costeiros, com as plantas geralmente exibindo sistema radicular superficial e enovelamento da raiz principal. Segundo esses autores, isso se deve à elevada resistência do solo à penetração e também à extirpação da raiz pivotante por ocasião do preparo das mudas, procedimento tradicional na região. Esses fatos, associados aos constantes períodos de estiagem que ocorrem durante o ano, causam prejuízos à produtividade e à longevidade da cultura dos citros (Carvalho et al., 1999).

Em estudo envolvendo a distribuição do sistema radicular de citros realizado no Estado de São Paulo, Montenegro (1960) observou, em solo com horizonte de impedimento temporário à drenagem, a $0,90 \mathrm{~m}$ de profundidade, restrição ao crescimento de raízes até esta profundidade, com a maior concentração (85 \%) do sistema radicular na profundidade de $0-0,30 \mathrm{~m}$. Em outro solo, sem qualquer impedimento, o sistema radicular distribuiu-se mais uniformemente no perfil, 
atingindo até $1,50 \mathrm{~m}$ de profundidade. Resultados semelhantes foram apresentados por Castle et al. (1993), obtidos na Flórida (EUA).

Em um perfil de Argissolo Acinzentado de tabuleiro, Cintra \& Libardi (1998) observaram valor mais elevado de densidade do solo $\left(1,72 \mathrm{~kg} \mathrm{dm}^{-3}\right)$ e menor para porosidade total $\left(0,34 \mathrm{~m}^{3} \mathrm{~m}^{-3}\right)$ no horizonte BA $(0,20-0,42 \mathrm{~m})$, confirmando a coesão nesse horizonte. A avaliação da distribuição do sistema radicular de cinco porta-enxertos de citros nesse mesmo solo mostrou que, em função da restrição ao aprofundamento do sistema radicular imposta pela camada coesa, em média $61 \%$ das raízes localizaram-se na profundidade de $0-0,20 \mathrm{~m}$ e $90 \%$ na de $0-0,40 \mathrm{~m}$ (Cintra et al., 1999). Resultados semelhantes foram obtidos por Carvalho et al. (1999), Souza et al. (2004a) e Santana et al. (2006), também em solos coesos de tabuleiro. A profundidade efetiva das raízes de citros, até onde se encontraram $80 \%$ das raízes, foi de 0,60 a $0,90 \mathrm{~m}$ para laranjeira 'Pêra' enxertada em limoeiro 'Cravo', em Mogi-Guaçú-SP, em solo de transição entre Latossolo Vermelho-Amarelo/Latossolo Roxo (Moreira, 1983); 0,50 a 0,75 m para tangerineira 'Poncã' enxertada em limoeiro 'Cravo', em Londrina-PR, em Latossolo Roxo (Neves et al., 1998); 0,60 m para laranjeira 'Pêra' enxertada em tangerineira 'Cleópatra', em Comendador Gomes-MG, em solo franco-arenoso (Oliveira et al., 1998); 0,40 m para lima ácida 'Tahiti' enxertada em limoeiro 'Cravo', em Piracicaba-SP, em Terra Roxa Estruturada (Machado \& Coelho, 2000); e de 0,31 a $0,53 \mathrm{~m}$ na linha de plantio e de 0,67 a $0,68 \mathrm{~m}$ na entrelinha, para lima ácida 'Tahiti' enxertada em seis diferentes porta-enxertos, em Maringá-PR, em Latossolo Vermelho (Neves et al., 2004). A distância efetiva, até onde se encontraram $80 \%$ das raízes a partir do tronco, foi de 1,25 a 2,00 m (Neves et al., 1998), 1,65 m (Oliveira et al., 1998), 2,25 m (Machado \& Coelho, 2000) e 1,69 a 2,54 m na linha de plantio e de 3,12 a 3,48 m na entrelinha (Neves et al., 2004).

Com relação à funcionalidade das raízes de citros, Santos et al. (2005) observaram que as raízes com diâmetro entre 0,5 e $2 \mathrm{~mm}$ foram as que mais extraíram água do solo.

O aumento da profundidade da cova de plantio de citros foi avaliado por Souza et al. (2006) como uma estratégia para romper a zona de coesão e aumentar o volume de solo ocupado pelas raízes, observando melhores resultados na linha de plantio para as profundidades de cova de 0,80 m, 1,00 m e 1,20 m, em relação a $0,40 \mathrm{~m}$ e 0,60 m. Esses resultados são muito importantes na medida em que Souza et al. (2004b) observaram que há maior disponibilidade de água para as plantas, nos solos de tabuleiro, a partir da profundidade de $0,90 \mathrm{~m}$. No entanto, Souza et al. (2004a) relataram que o aprofundamento do sistema radicular, explorando maior volume de solo e maior quantidade de água disponível, não é suficiente para viabilizar o aumento de produtividade de citros, sem melhoria nas condições químicas do solo de tabuleiro. $\mathrm{O}$ manejo do solo, representado pelo controle químico das plantas daninhas nas linhas de plantio e o plantio de feijão-de-porco (Canavalia ensiformis) nas entrelinhas do pomar, no período das águas, proporcionou diminuição da densidade do solo, aumento da porosidade, infiltração e armazenamento de água no solo, além de maior crescimento e aprofundamento do sistema radicular e melhor produtividade da laranjeira (Carvalho et al., 1999).

Rezende et al. (2002), trabalhando com subsolagem em solo de tabuleiro, citam dados mostrando que plantas de tangor Murcott mais desenvolvidas, vigorosas, produtivas e com frutos de melhor qualidade foram aquelas cujas raízes exploraram maior volume de solo sob o efeito das hastes subsoladoras. Já Bordin et al. (2005) não observaram alterações na densidade e porosidade total do solo nas entrelinhas de pomar de citros e na quantidade de raízes, independente da profundidade e da posição em relação à planta, três anos depois da escarificação a $0,30 \mathrm{~m}$ de profundidade. Os efeitos da compactação, que são semelhantes aos da coesão, promovem redução da macroporosidade, da água disponível e do desenvolvimento do sistema radicular em citros (Mazza et al., 1994), inferindo também, em conseqüência, efeitos negativos na absorção de nutrientes e na produtividade.

Em estudo com citros durante o ano de 1996, em toposseqüência em área de tabuleiro localizada em Sapeaçu (BA), composta por Latossolo Amarelo Argissólico-LAx (terço superior), Argissolo AmareloPAx (terço médio), ambos coesos, e Argissolo Acinzentado-PAC (terço inferior), não coeso, Paiva et al. (1998) observaram períodos de seis quinzenas em 1996 sem água disponível para as plantas (água retida abaixo de -1,5 $\mathrm{MPa}$ ) até a profundidade de $1,50 \mathrm{~m}$ no LAx e de 10 quinzenas no PAx; já o PAC, não coeso, apresentou água disponível durante todo o período considerado. As plantas cítricas localizadas neste último solo apresentaram crescimento vegetativo (diâmetro do caule, altura da planta e circunferência da copa) estatisticamente superior ao daquelas localizadas nos outros dois solos. Nos perfis de solo examinados, observaram-se raízes de citros até $1,50 \mathrm{~m}$ de profundidade no PAC, pelo fato de não apresentar restrição física ao aprofundamento do sistema radicular, o que não ocorreu nos outros dois solos. Essas são explicações para o maior crescimento das plantas no PAC, apesar de apresentar menor fertilidade química que os demais solos avaliados.

Em continuidade, o objetivo deste trabalho foi avaliar a distribuição vertical e horizontal do sistema radicular de citros em solos coesos e não coesos dos Tabuleiros Costeiros, de forma a reunir informações que possam auxiliar na orientação de práticas de manejo.

\section{MATERIAL E MÉTODOS}

O trabalho foi desenvolvido na Fazenda Soledade, em uma área com pomar de laranjeira 'Hamlin' 
enxertada em limoeiro 'Cravo', com 15 anos de idade, situada no Município de Sapeaçu, Recôncavo Baiano, a $12^{\circ} 45^{\prime}$ de latitude sul e $39^{\circ} 15^{\prime}$ 'de longitude oeste, em uma toposseqüência de tabuleiro com $190 \mathrm{~m}$ de comprimento e declividade média de $0,097 \mathrm{~m} \mathrm{~m}^{-1}$, composta por Latossolo Amarelo Argissólico-LAx (terço superior), Argissolo Amarelo-PAx (terço médio), ambos coesos, e Argissolo Acinzentado-PAC (terço inferior), não coeso. O pomar foi implantado no espaçamento de $5 \times 4 \mathrm{~m}$, sendo manejado por meio de três a cinco capinas manuais na linha e igual número de gradagens nas entrelinhas, por ano.

Pela classificação de Thornthwaite, o clima de Sapeaçu é considerado seco a subúmido, com temperatura média anual de $24,3{ }^{\circ} \mathrm{C}$. A pluviosidade anual varia de 800 a $1.200 \mathrm{~mm}$, e os meses de abril a junho correspondem ao maior período chuvoso, e de outubro a janeiro ao período mais seco (CEI, 1994). Dados médios de precipitação pluviométrica da região, do período de 1971 a 2005, são apresentados na figura 1. Embora esses dados tenham sido coletados em Cruz das Almas, distante $20 \mathrm{~km}$ da área experimental, podese considerar válido o seu uso, pela boa relação obtida por Paiva (1997) entre tais dados e a umidade do solo medida semanalmente.

Foi descrito e amostrado um perfil para cada solo, coletando-se material de solo em cada horizonte para análises físicas e químicas, perfazendo um total de 12 horizontes, com três repetições por horizonte. Os solos LAx e PAx apresentaram horizontes morfologicamente considerados coesos, com estrutura maciça e consistência variando de dura a extremamente dura quando secos. A análise granulométrica foi realizada pelo método do hidrômetro de Bouyoucos, utilizando o hidróxido de sódio como dispersante, e a densidade do solo determinada pelo método do cilindro volumétrico (Embrapa, 1997). A porosidade total, macroporosidade e microporosidade foram obtidas pelo método da mesa de tensão (Oliveira, 1968), utilizando amostras indeformadas em anéis com volume de $313,97 \mathrm{~cm}^{3}$. As análises químicas foram realizadas conforme métodos descritos em Embrapa (1997).

O baixo número de unidades experimentais é característico em trabalhos sobre raízes de citros, devido ao elevado volume de amostras gerado, resultando em enorme esforço no campo, além de o processamento ser muito trabalhoso. Este fato pode ser bem observado nos trabalhos de Carvalho et al. (1999), Cintra et al. (1999) e Coelho et al. (2002). Assim, na toposseqüência citada, foram inicialmente retiradas amostras de raízes em uma planta localizada no LAx e em outra no PAx, ambos coesos, e em duas no PAC, não coeso. Pelo fato de o LAx e o PAx apresentarem características físicas e morfológicas semelhantes, admitiu-se a possibilidade de os resultados obtidos nesses dois solos serem também semelhantes, o que permitiria considerar as duas plantas amostradas como repetições entre si. Como isto se confirmou em análise preliminar dos resultados, desistiu-se de amostrar mais uma planta em cada um dos solos coesos, como estava previsto.

As raízes foram coletadas em setembro de 2001, mês em que choveu $140 \mathrm{~mm}$, em quatro horizontes e em dois planos perpendiculares do solo (linha e entrelinha), de maneira semelhante a um sistema de eixos cartesianos com a planta no ponto zero. Partindo deste ponto, o primeiro local de amostragem foi a 0,50 $\mathrm{m}$ do tronco, seguindo de 0,50 em 0,50 $\mathrm{m}$ até a distância média da próxima planta, ou seja, como os pomares foram instalados no espaçamento de $5,0 \times 4,0 \mathrm{~m}$, foram amostrados quatro pontos no sentido da linha e cinco pontos no sentido da entrelinha (Figura 2), totalizando 144 amostras. As profundidades e características químicas dos horizontes amostrados em cada solo estão detalhadas no quadro 1. Para a coleta das amostras, utilizou-se um cilindro inteiriço de aço de 1,20 m de comprimento, $0,085 \mathrm{~m}$ de diâmetro e uma ranhura lateral para facilitar a retirada do solo + raízes, o qual foi introduzido no solo com umidade suficiente para

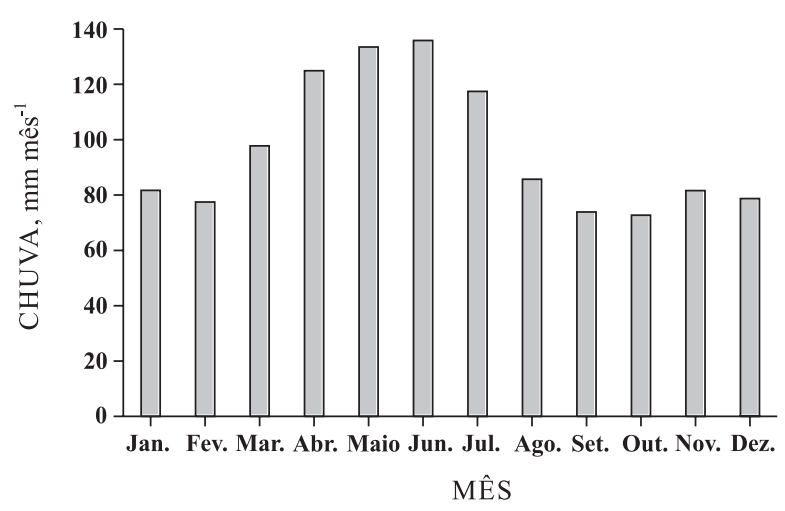

Figura 1. Dados de precipitação pluviométrica na região de Sapeaçu (BA), média de 1971 a 2005.

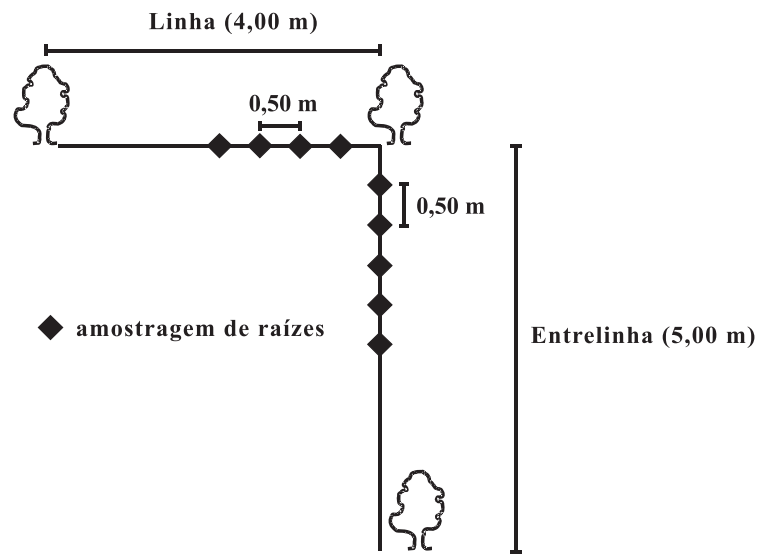

Figura 2. Esquema de amostragem de raízes de citros em uma toposseqüência de solos de tabuleiro costeiro, localizada em Sapeaçu (BA). 
favorecer tal amostragem. Em cada planta amostrada, inicialmente o cilindro foi cravado até atingir a espessura do horizonte superficial de cada um dos solos avaliados, consecutivamente em todos os nove pontos de amostragem, sendo então retirado o cilindro em cada ponto e recolhido o solo + raízes amostradas, o que foi feito com o auxílio de uma faca, quando necessário. Em seguida, nos mesmos orifícios, o cilindro foi novamente cravado até atingir a espessura do segundo horizonte, também nos nove pontos de amostragem, e assim por diante até atingir o último horizonte amostrado em cada solo. As raízes foram separadas do solo por lavagem em peneira de malha fina e secas ao ar. As imagens digitalizadas das raízes em escaner foram processadas no aplicativo GSRoot (Guddanti \& Chambers, 1993), obtendo-se o comprimento de raízes para as classes de diâmetro de $<1,1-2$ e $>2 \mathrm{~mm}$. Como a profundidade/espessura dos horizontes variou entre solos, expressaram os dados em densidade de raízes no solo, ou seja, em cm de raízes por $\mathrm{cm}^{3}$ de solo.

Os dados médios para densidade total de raízes, globalizando as três classes de diâmetro avaliadas, para os solos, horizontes e locais de amostragem, foram comparados entre si pelo teste t a $5 \%$ de erro, como também os diferentes solos dentro de cada horizonte, usando-se o aplicativo Saeg, versão 5 .

Foi também realizada a distribuição espacial da densidade total de raízes para cada um dos solos, utilizando-se o aplicativo Surfer, versão 7.

\section{RESULTADOS E DISCUSSÃO}

A análise química dos solos avaliados (Quadro 1) mostrou que, de maneira geral, o Argissolo Acinzentado (PAC) apresentou menor capacidade de suprimento de nutrientes do que o Latossolo Amarelo Argissólico (LAx) e Argissolo Amarelo (PAx).

Observa-se, pelos dados morfológicos e físicos dos solos avaliados (Quadro 2), que o PAC, não coeso, é mais arenoso do que os demais. Embora sua porosidade total seja semelhante ao LAx e PAx, sua macroporosidade é bem mais elevada e a microporosidade é bem menor. No LAx e no PAx, houve acentuada predominância de microporos sobre macroporos, com a maioria dos valores de macroporos inferior a $0,10 \mathrm{~m}^{3} \mathrm{~m}^{-3}$, que, se-

Quadro 1. Resultados de análises químicas de uma toposseqüência de solos de tabuleiro cultivados com citros

\begin{tabular}{|c|c|c|c|c|c|c|c|c|c|}
\hline Horizonte & $\mathrm{pH} \mathrm{H}_{2} \mathrm{O}$ & $\mathbf{P}$ & $\mathbf{K}^{+}$ & $\mathrm{Ca}^{2+}$ & $\mathbf{M g}^{2+}$ & $\mathbf{C T C} \mathbf{C}^{(1)}$ & $\mathbf{V}$ & $\mathbf{m}$ & MO \\
\hline $\mathrm{m}$ & & \multicolumn{2}{|c|}{$-\mathrm{mg} \mathrm{kg}^{-1}-$} & \multicolumn{3}{|c|}{$\operatorname{mmol}_{\mathrm{c}} \mathrm{kg}^{-1}$} & \multicolumn{2}{|c|}{$-\%$} & $\mathrm{~g} \mathrm{~kg}^{-1}$ \\
\hline \multicolumn{10}{|c|}{ Latossolo Amarelo argissólico (LAx) coeso } \\
\hline Ap $(0-0,18)$ & 5,8 & 20 & 188 & 21 & 20 & 78 & 59 & 4 & 21 \\
\hline $\mathrm{AB}(0,18-0,46)$ & 4,9 & 4 & 186 & 7 & 6 & 77 & 25 & 37 & 15 \\
\hline $\mathrm{BA}(0,46-0,80)$ & 4,4 & 1 & 172 & 4 & 4 & 65 & 20 & 52 & 10 \\
\hline Bw1 $(0,80-1,50)$ & 4,4 & 0 & 139 & 7 & 6 & 52 & 33 & 35 & 6 \\
\hline $\mathrm{Bw} 2(1,50-1,60+)$ & 4,7 & 0 & 48 & 10 & 7 & 44 & 43 & 21 & 5 \\
\hline \multicolumn{10}{|c|}{ Argissolo Amarelo (PAx) coeso } \\
\hline Ap $(0-0,20)$ & 5,8 & 19 & 216 & 20 & 11 & 71 & 52 & 10 & 18 \\
\hline $\mathrm{AB}(0,20-0,46)$ & 4,9 & 1 & 162 & 12 & 7 & 73 & 34 & 24 & 13 \\
\hline $\mathrm{BA}(0,46-0,67)$ & 4,4 & 0 & 83 & 16 & 8 & 72 & 39 & 22 & 14 \\
\hline Bt1 $(0,67-1,03)$ & 4,2 & 0 & 29 & 15 & 8 & 63 & 40 & 24 & 8 \\
\hline Bt2 $(1,03-1,24)$ & 4,2 & 0 & 16 & 14 & 8 & 56 & 43 & 20 & 6 \\
\hline $\mathrm{BC}(1,24-1,50+)$ & 4,2 & 0 & 9 & 14 & 9 & 46 & 52 & 11 & 4 \\
\hline \multicolumn{10}{|c|}{ Argissolo Acinzentado (PAC) não coeso } \\
\hline Ap $(0-0,30)$ & 6,4 & 14 & 39 & 9 & 5 & 25 & 60 & 0 & 4 \\
\hline $\mathrm{AE}(0,30-0,70)$ & 5,2 & 3 & 14 & 4 & 2 & 22 & 32 & 30 & 3 \\
\hline $\mathrm{E} 1(0,70-0,87)$ & 5,1 & 1 & 14 & 2 & 1 & 15 & 27 & 43 & 2 \\
\hline $\mathrm{E} 2(0,87-1,05)$ & 5,3 & 1 & 6 & 1 & 2 & 11 & 27 & 40 & 1 \\
\hline E3 $(1,05-1,30)$ & 5,3 & 0 & 11 & 1 & 1 & 10 & 30 & 40 & 1 \\
\hline Bt $(1,30-1,50+)$ & 4,7 & 0 & 12 & 2 & 2 & 19 & 26 & 44 & 1 \\
\hline
\end{tabular}

(1) CTC: capacidade de troca catiônica; V: saturação por bases; m: saturação por alumínio; MO: matéria orgânica. 
Quadro 2. Dados morfológicos e físicos de uma toposseqüência de solos de tabuleiro cultivados com citros

\begin{tabular}{|c|c|c|c|c|c|c|c|c|c|}
\hline \multirow{2}{*}{ Horizonte } & \multirow{2}{*}{ Estrutura } & \multirow{2}{*}{ Consistência } & \multirow{2}{*}{ Areia } & \multirow{2}{*}{ Silte } & \multirow{2}{*}{ Argila } & \multicolumn{3}{|c|}{ Porosidade } & \multirow{2}{*}{ Densidade } \\
\hline & & & & & & Total & Macro & Micro & \\
\hline \multirow[t]{2}{*}{$\mathrm{m}$} & & & - & $\mathrm{g} \mathrm{kg}^{-1}$ & - & $\longrightarrow$ & $-m^{3} m^{-3}$ & - & $\mathrm{kg} \mathrm{dm}^{-3}$ \\
\hline & \multicolumn{9}{|c|}{ Latossolo Amarelo argissólico (LAx) coeso } \\
\hline Ap $(0-0,18)$ & $\begin{array}{l}\text { blocos subangulares } \\
\text { pequenos e médios }\end{array}$ & $\begin{array}{l}\text { macio, muito friável, } \\
\text { ligeiramente plástico, } \\
\text { ligeiramente pegajoso }\end{array}$ & 615 & 116 & 269 & 0,35 & 0,11 & 0,24 & 1,57 \\
\hline $\mathrm{AB}(0,18-0,46)$ & $\begin{array}{l}\text { maciço que se desfaz em } \\
\text { blocos subangulares }\end{array}$ & $\begin{array}{l}\text { duro, firme, } \\
\text { ligeiramente plástico, } \\
\text { ligeiramente pegajoso }\end{array}$ & 526 & 103 & 371 & 0,34 & 0,08 & 0,26 & 1,59 \\
\hline $\mathrm{BA}(0,46-0,80)$ & $\begin{array}{l}\text { maciço que se desfaz em } \\
\text { fragmentos angulosos }\end{array}$ & $\begin{array}{l}\text { duro, friável, plástico, } \\
\text { ligeiramente pegajoso }\end{array}$ & 444 & 90 & 466 & 0,37 & 0,09 & 0,28 & 1,55 \\
\hline Bw1 $(0,80-1,50)$ & $\begin{array}{l}\text { forte, pequena, } \\
\text { granular, e blocos } \\
\text { subangulares pequenos } \\
\text { e médios }\end{array}$ & $\begin{array}{l}\text { extremamente duro, } \\
\text { firme, ligeiramente } \\
\text { plástico, ligeiramente } \\
\text { pegajoso }\end{array}$ & 375 & 106 & 519 & 0,35 & 0,03 & 0,32 & 1,57 \\
\hline \multirow[t]{2}{*}{ Bw2 $(1,50-1,60+)$} & $\begin{array}{l}\text { forte, pequena, } \\
\text { granular, e blocos } \\
\text { subangulares pequenos } \\
\text { e médios }\end{array}$ & $\begin{array}{l}\text { duro, friável, plástico, } \\
\text { ligeiramente plástico, } \\
\text { ligeiramente pegajoso }\end{array}$ & 353 & 144 & 503 & 0,42 & 0,11 & 0,31 & 1,40 \\
\hline & \multicolumn{9}{|c|}{ Argissolo Amarelo (PAx) coeso } \\
\hline Ap $(0-0,20)$ & blocos subangulares & $\begin{array}{l}\text { ligeiramente duro, } \\
\text { firme, ligeiramente } \\
\text { plástico, ligeiramente } \\
\text { pegajoso }\end{array}$ & 660 & 111 & 229 & 0,31 & 0,08 & 0,23 & 1,72 \\
\hline $\mathrm{AB}(0,20-0,46)$ & $\begin{array}{l}\text { maciço que se desfaz em } \\
\text { blocos subangulares }\end{array}$ & $\begin{array}{l}\text { duro, firme, } \\
\text { ligeiramente plástico, } \\
\text { ligeiramente pegajoso }\end{array}$ & 538 & 111 & 351 & 0,33 & 0,05 & 0,28 & 1,64 \\
\hline BA $(0,46-0,67)$ & $\begin{array}{l}\text { maciço que se desfaz em } \\
\text { blocos subangulares }\end{array}$ & $\begin{array}{l}\text { duro, muito firme, } \\
\text { ligeiramente plástico, } \\
\text { ligeiramente pegajoso }\end{array}$ & 433 & 101 & 466 & 0,31 & 0,01 & 0,30 & 1,68 \\
\hline $\operatorname{Bt} 1(0,67-1,03)$ & blocos angulares & $\begin{array}{l}\text { muito duro, muito } \\
\text { firme, plástico, pegajoso }\end{array}$ & 396 & 104 & 500 & 0,35 & 0,03 & 0,32 & 1,55 \\
\hline Bt2 $(1,03-1,24)$ & blocos angulares & $\begin{array}{l}\text { muito duro, muito } \\
\text { firme, plástico, pegajoso }\end{array}$ & 390 & 155 & 455 & 0,36 & 0,03 & 0,33 & 1,53 \\
\hline \multirow[t]{2}{*}{$\mathrm{BC}(1,24-1,50+)$} & $\begin{array}{l}\text { blocos angulosos com } \\
\text { manchas de alteração } \\
\text { do material de origem }\end{array}$ & $\begin{array}{l}\text { muito duro, plástico, } \\
\text { ligeiramente pegajoso }\end{array}$ & 362 & 155 & 483 & 0,36 & 0,03 & 0,33 & 1,53 \\
\hline & \multicolumn{9}{|c|}{ Argissolo Acinzentado (PAC) não coeso } \\
\hline Ap $(0-0,30)$ & $\begin{array}{l}\text { grãos simples, e fraca, } \\
\text { pequena, blocos } \\
\text { subangulares }\end{array}$ & $\begin{array}{l}\text { ligeiramente duro, } \\
\text { muito friável, não } \\
\text { plástico, não pegajoso }\end{array}$ & 834 & 116 & 50 & 0,37 & 0,22 & 0,15 & 1,63 \\
\hline $\operatorname{AE}(0,30-0,70)$ & $\begin{array}{l}\text { aspecto maciço, com } \\
\text { grãos simples, com } \\
\text { raras, fraca, pequena, } \\
\text { média, blocos } \\
\text { subangulares }\end{array}$ & $\begin{array}{l}\text { ligeiramente duro, } \\
\text { muito friável, não } \\
\text { plástico, não pegajoso }\end{array}$ & 808 & 139 & 53 & 0,36 & 0,20 & 0,16 & 1,70 \\
\hline E1 $(0,70-0,87)$ & $\begin{array}{l}\text { maciço quebrando-se em } \\
\text { fragmentos } \\
\text { subangulosos e } \\
\text { angulosos }\end{array}$ & $\begin{array}{l}\text { ligeiramente duro, } \\
\text { muito friável, não } \\
\text { plástico, não pegajoso }\end{array}$ & 829 & 134 & 37 & 0,36 & 0,19 & 0,17 & 1,71 \\
\hline E2 $(0,87-1,05)$ & $\begin{array}{l}\text { maciço quebrando-se em } \\
\text { fragmentos } \\
\text { subangulosos e } \\
\text { angulosos }\end{array}$ & $\begin{array}{l}\text { ligeiramente duro, solto, } \\
\text { não plástico, não } \\
\text { pegajoso }\end{array}$ & 841 & 136 & 23 & 0,35 & 0,18 & 0,17 & 1,73 \\
\hline E3 $(1,05-1,30)$ & $\begin{array}{l}\text { maciço quebrando-se em } \\
\text { fragmentos } \\
\text { subangulosos e } \\
\text { angulosos }\end{array}$ & $\begin{array}{l}\text { duro, muito friável, não- } \\
\text { plástico, não pegajoso }\end{array}$ & 837 & 140 & 23 & 0,35 & 0,20 & 0,15 & 1,74 \\
\hline Bt $(1,30-1,50+)$ & $\begin{array}{l}\text { maciço que se desfaz em } \\
\text { fragmentos angulosos }\end{array}$ & $\begin{array}{l}\text { extremamente duro, } \\
\text { extremamente firme, } \\
\text { não-plástico, } \\
\text { ligeiramente pegajoso }\end{array}$ & 752 & 144 & 104 & 0,32 & 0,16 & 0,16 & 1,79 \\
\hline
\end{tabular}


gundo Carter (2002), é o limite crítico para o crescimento e desenvolvimento radicular. De modo geral, a densidade do solo apresentou valores mais elevados no PAC, apesar de não ser coeso, o que foi atribuído à textura arenosa e ao menor teor de matéria orgânica, resultando em maior densidade das partículas e menor agregação (Paiva, 1997) para os solos avaliados; isso faz com que as partículas se apresentem muito unidas entre si, resultando em maior densidade do solo (Brady, 1989).

O teste de médias realizado para densidade total de raízes de citros mostrou diferenças significativas entre os solos e entre os horizontes, e não significativas para locais de amostragem (Quadro 3).

Analisando os valores médios de densidade de raízes de citros, por horizonte, para os solos estudados (Figura 3), observaram-se valores bem mais elevados no solo PAC, não coeso, variando de 3,4 a 4,1 vezes superiores aos dos solos coesos, respectivamente. A densidade de raízes nos horizontes superficiais do LAx e PAx foi bastante aproximada daquela observada no horizonte mais profundo do solo PAC. Esses dados

Quadro 3. Comparações entre médias de densidade total de raízes de citros, totalizando as três classes de diâmetro avaliadas, para solos, horizontes e locais de amostragem em uma toposseqüência de solos de tabuleiro cultivados com citros, localizada em Sapeaçu (BA), composta por Latossolo Amarelo argissólico (LAx), Argissolo Amarelo (PAx), ambos coesos, e Argissolo Acinzentado (PAC), não coeso

\begin{tabular}{|c|c|}
\hline Variáveis & $\begin{array}{c}\text { Densidade de } \\
\text { raízes } \\
{\text { (cm de raízes } \mathrm{cm}^{-3}}_{\text {de solo })^{(1)}}\end{array}$ \\
\hline \multicolumn{2}{|l|}{ Solos } \\
\hline LAx & $0,087 \mathrm{~b}$ \\
\hline PAx & $0,071 \mathrm{~b}$ \\
\hline $\mathrm{PAC}$ & $0,294 \mathrm{a}$ \\
\hline \multicolumn{2}{|l|}{ Horizontes } \\
\hline Ap (LAx, PAx e PAC) & $0,311 \mathrm{a}$ \\
\hline $\mathrm{AB}(\mathrm{LAx}$ e $\mathrm{PAx})$ e $\mathrm{AE}(\mathrm{PAC})$ & $0,100 \mathrm{~b}$ \\
\hline $\mathrm{BA}(\mathrm{LAx}$ e PAx) e E1 (PAC) & $0,112 \mathrm{~b}$ \\
\hline $\mathrm{Bw} 1(\mathrm{LAx}), \mathrm{Bt} 1(\mathrm{PAx})$ e E2 (PAC) & $0,078 \mathrm{~b}$ \\
\hline \multicolumn{2}{|c|}{ Locais de amostragem $^{(2)}$} \\
\hline $0,5 \mathrm{~L}$ & 0,163 a \\
\hline $1,0 \mathrm{~L}$ & $0,108 \mathrm{a}$ \\
\hline $1,5 \mathrm{~L}$ & $0,139 \mathrm{a}$ \\
\hline $2,0 \mathrm{~L}$ & $0,156 \mathrm{a}$ \\
\hline $0,5 \mathrm{EL}$ & $0,141 \mathrm{a}$ \\
\hline $1,0 \mathrm{EL}$ & $0,142 \mathrm{a}$ \\
\hline $1,5 \mathrm{EL}$ & $0,175 \mathrm{a}$ \\
\hline $2,0 \mathrm{EL}$ & $0,147 \mathrm{a}$ \\
\hline $2,5 \mathrm{EL}$ & $0,185 \mathrm{a}$ \\
\hline
\end{tabular}

(1) Médias seguidas pela mesma letra na coluna, dentro de solos, horizontes e locais de amostragem, não diferem significativamente entre si, pelo teste t a $5 \%$. ${ }^{(2)}$ Distância da planta, em metros, na linha (L) e na entrelinha (EL). confirmam que a coesão realmente constitui-se em severa restrição ao crescimento e aprofundamento do sistema radicular de citros (Carvalho et al., 1999; Cintra et al., 1999; Rezende et al., 2002; Santana et al., 2006). Montenegro (1960) e Castle et al. (1993) também observaram essa restrição em solos com impedimento à drenagem.

Santos (2005) observou que as raízes de citros com diâmetros entre 0,5 e $2 \mathrm{~mm}$ foram as que mais extraíram água do solo, sendo assim mais eficientes no suprimento de água e nutrientes para as plantas cítricas. Isso reforça os dados obtidos neste trabalho, no qual se observou a predominância de raízes com diâmetros $<1 \mathrm{~mm}$, seguidas pelas de 1-2 $\mathrm{mm}$ e, por último, as $>2 \mathrm{~mm}$ (Figura 3).

No quadro 4, observa-se que a maior profundidade efetiva do sistema radicular, até onde se encontraram $80 \%$ das raízes, foi observada no $\mathrm{PAC}$, não coeso $(0,80 \mathrm{~m})$, suplantando os valores observados por Moreira (1983), Neves et al. (1998, 2004), Oliveira et al. (1998) e Machado \& Coelho (2000), possivelmente pelo fato de que esses autores trabalharam em solos com maiores restrições ao aprofundamento do sistema radicular de citros do que o PAC.

A maior distância efetiva, até onde se encontraram $80 \%$ das raízes a partir do tronco, ocorreu no solo PAx $(2,21 \mathrm{~m})$, sendo o que apresentou a menor profundidade efetiva $(0,59 \mathrm{~m})$, permitindo pressupor que a restrição ao crescimento vertical favoreceu o crescimento horizontal, o que pode ser comprovado pela baixa macroporosidade verificada em todo o perfil do solo (Quadro 2). Essas informações são importantes para a localização de adubos em pomares adultos e para o planejamento/dimensionamento de projetos de irrigação.

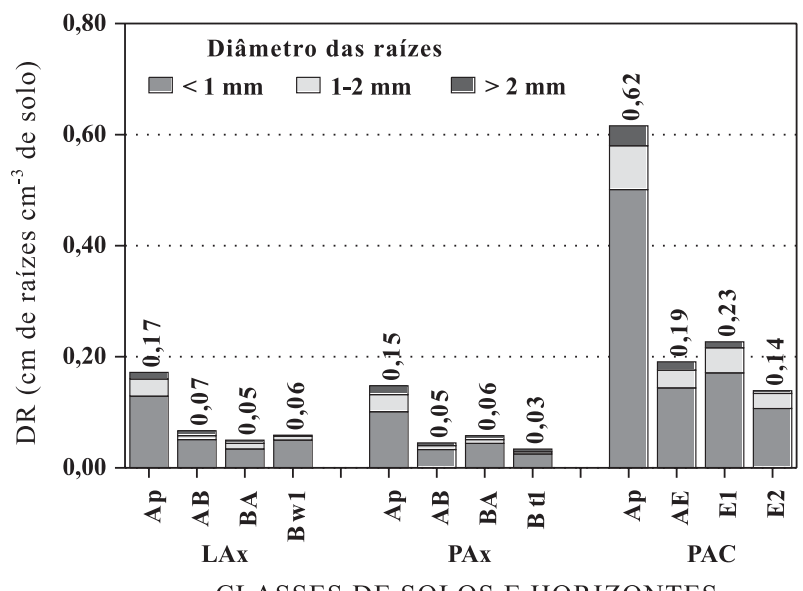

Figura 3. Valores médios de densidade de raízes da laranjeira 'Hamlin' enxertada em limoeiro 'Cravo", em três classes de diâmetro, por horizonte, em uma toposseqüência de solos de tabuleiro, localizada em Sapeaçu (BA), composta por Latossolo Amarelo argissólico (LAx), Argissolo Amarelo (PAx), ambos coesos, e Argissolo Acinzentado (PAC), não coeso. 
Quadro 4. Profundidade e distância efetivas do sistema radicular de citros, em uma toposseqüência de solos de tabuleiro cultivados com citros, localizada em Sapeaçu (BA), composta por Latossolo Amarelo argissólico (LAx), Argissolo Amarelo (PAx), ambos coesos, e Argissolo Acinzentado (PAC), não coeso

\begin{tabular}{lll}
\hline \multicolumn{1}{c}{ Solo } & Profundidade Distância \\
\cline { 2 - 3 } & & \multicolumn{2}{c}{$\mathrm{m}-$} \\
Latossolo Amarelo argissólico & 0,73 & 2,05 \\
Argissolo Amarelo & 0,59 & 2,21 \\
Argissolo Acinzentado & 0,80 & 2,04 \\
\hline
\end{tabular}

O valor médio da densidade total de raízes encontrada no horizonte Ap, referente ao agrupamento dos três solos, apresentou-se estatisticamente superior aos dos demais horizontes (Quadro 3), sendo reflexo da maior macroporosidade e menor microporosidade encontradas no horizonte superficial dos três solos, em relação aos respectivos horizontes subjacentes (Quadro 2). Os demais horizontes não apresentaram diferença significativa entre si, nem as densidades de raízes observadas nos diferentes locais de amostragem, na linha e entrelinha (Quadro 3), o que pressupõe semelhança nas características físicas do solo nesses dois ambientes e reforça a utilização dos dados amostrados apenas nas entrelinhas.

Os resultados apresentados quantificam e confirmam a influência negativa e relativa da coesão do solo no crescimento e no aprofundamento do sistema radicular de citros. Rezende et al. (2002) relatam que o pouco aprofundamento das raízes de citros em solos coesos deve-se à extirpação da raiz pivotante por ocasião do preparo das mudas. Os resultados mostram que são necessários mais estudos, desde quando no solo PAC, cujas mudas também foram obtidas por esse mesmo procedimento, não houve problemas de crescimento e aprofundamento das raízes. É mais coerente admitir que as raízes das plantas cítricas são muito sensíveis à coesão do solo.

Na mesma toposseqüência estudada, foi observado que as plantas cítricas localizadas no PAC (terço inferior), não coeso, apresentaram crescimento estatisticamente superior ao daquelas localizadas no LAx (terço superior) e no PAx (terço médio), ambos coesos (Paiva et al., 1998). O fato de o PAC, neste estudo, ter apresentado maior densidade de raízes em todo o perfil, associado à presença de água disponível no solo até $1,50 \mathrm{~m}$ de profundidade durante todo o ano de avaliação, dados também observados por Paiva et al. (1998), são realmente as causas do maior crescimento das plantas neste solo, o que tem grande influência na redução da resistência do solo à penetração, favorecendo a expansão do sistema radicular, apesar de ter menor capacidade de suprimento de nutrientes que os demais solos avaliados (Quadro 1). Resultados semelhantes são citados por Rezende et al. (2002), para tangor Murcott. Coelho et al. (2002) observaram tal condição ao avaliar a distribuição de raízes de laranjeira 'Pêra' em solo sob condições irrigada e de sequeiro, em Latossolo Vermelho-Amarelo de tabuleiro, de textura arenosa, em Parnaíba (PI).

A importância do maior crescimento e aprofundamento do sistema radicular de citros em relação à produtividade também é enfatizada por Mazza et al. (1994), Carvalho et al. (1999) e Rezende et al. (2002). No entanto, Souza et al. (2004a) consideraram isso necessário, mas não suficiente, sendo também importante melhorar as condições químicas do solo, já que, no seu trabalho, o aumento de produtividade não acompanhou o aprofundamento do sistema radicular.

Os dados obtidos confirmam a conclusão apresentada por Souza (1997), isto é, qualquer interferência de uso e manejo no sentido de aumentar a produtividade das culturas nos solos coesos de tabuleiro deve ter, como premissas básicas, aumentar o crescimento e o aprofundamento do sistema radicular das culturas, além de melhorar a dinâmica e o armazenamento de água no perfil e corrigir a acidez e elevar os nutrientes para níveis adequados. Este último aspecto é também considerado essencial por Souza et al. (2004a).

A distribuição espacial das raízes no perfil avaliado, na linha e entrelinha, mostrou que, nos solos LAx e PAx, ambos coesos, a maior concentração de raízes na linha ocorreu a $0,50 \mathrm{~m}$ do tronco da planta e na camada de 0-0,20 m de profundidade (Figuras 4a e 5a). As menores concentrações de raízes foram observadas a partir de 0,40 m de profundidade em ambos os solos, coincidindo com a menor macroporosidade e maior microporosidade (Quadro 2). Nas entrelinhas (Figuras $4 \mathrm{~b}$ e 5b), a maior concentração de raízes foi observada também na camada de $0-0,20 \mathrm{~m}$ de profundidade e de 2,00 a $2,50 \mathrm{~m}$ de distância da planta, coincidindo com a faixa onde ocorre a maior freqüência de passagem de grade no controle das plantas daninhas. Esta operação promove o corte de raízes e o seu brotamento, justificando assim os resultados obtidos. Na entrelinha, as menores concentrações de raízes foram observadas também a partir de 0,40 $\mathrm{m}$ de profundidade.

No solo PAC, não coeso, de textura arenosa e com a porosidade total ocupada predominantemente por macroporos, as maiores concentrações de raízes foram observadas na camada de $0-0,20 \mathrm{~m}$ de profundidade e a 1,50-2,00 m de distância da planta na linha (Figura 6a) e entre 1,00 m e 2,50 m na entrelinha (Figura 6b). Em relação à distância da planta, a distribuição de raízes foi bem mais difusa do que nos solos LAx e PAx (Figuras 4 e 5), tanto na linha como na entrelinha, refletindo melhor distribuição espacial das raízes, sendo esta uma das causas, além da maior 

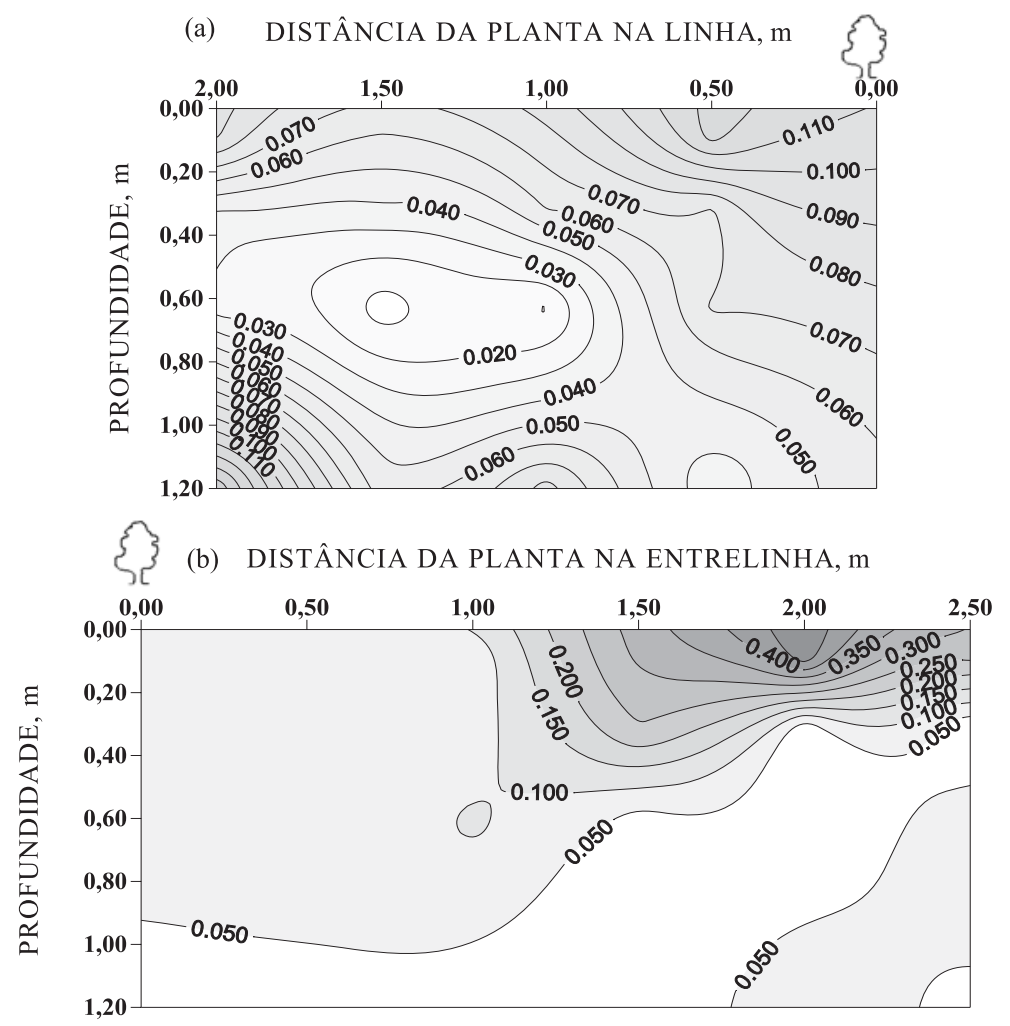

Figura 4. Distribuição espacial da densidade total de raízes da laranjeira 'Hamlin' enxertada em limoeiro 'Cravo", em cm de raízes por $\mathrm{cm}^{-3}$ de solo, no perfil de um Latossolo Amarelo Argissólico (LAx) coeso, em uma toposseqüência de solos de tabuleiro localizada em Sapeaçu (BA), (a) na linha e (b) na entrelinha.
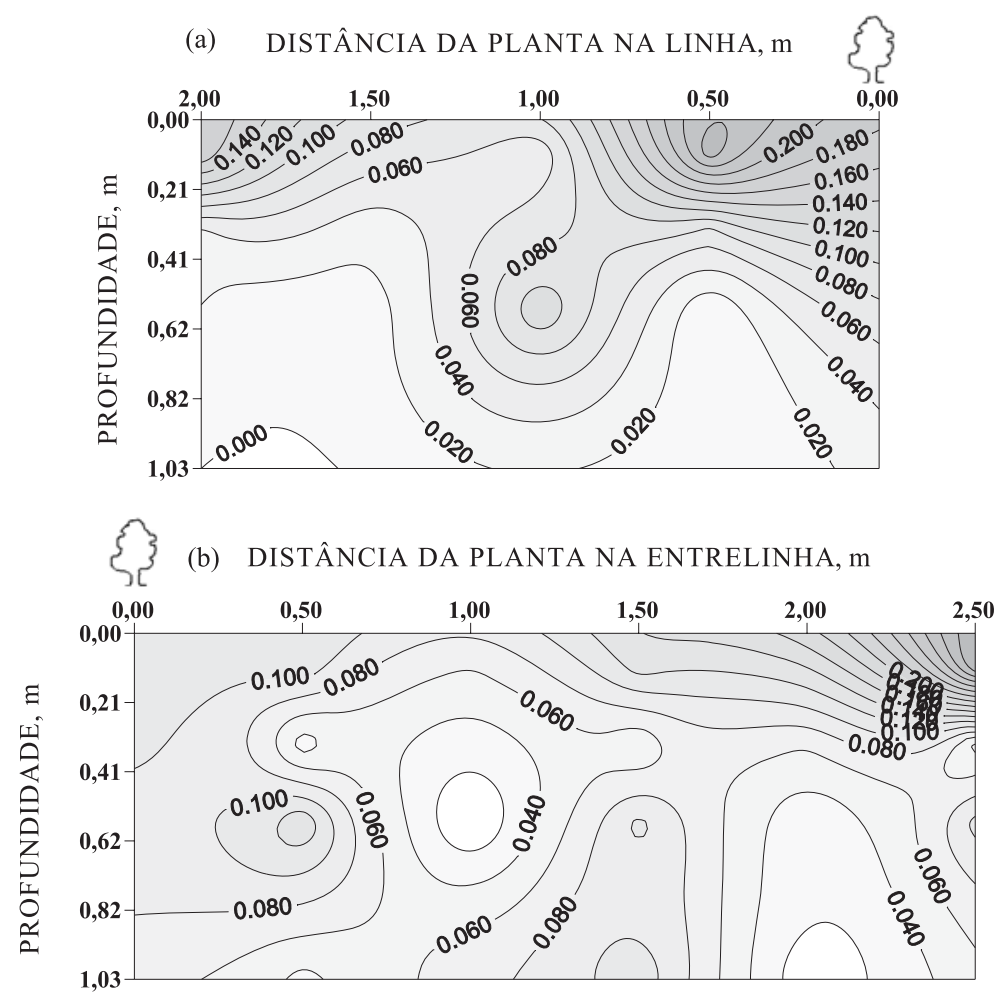

Figura 5. Distribuição espacial da densidade total de raízes da laranjeira 'Hamlin' enxertada em limoeiro "Cravo", em cm de raízes por $\mathrm{cm}^{-3}$ de solo, no perfil de um Argissolo Amarelo (PAx) coeso, em uma toposseqüência de solos de tabuleiro localizada em Sapeaçu (BA), (a) na linha e (b) na entrelinha. 

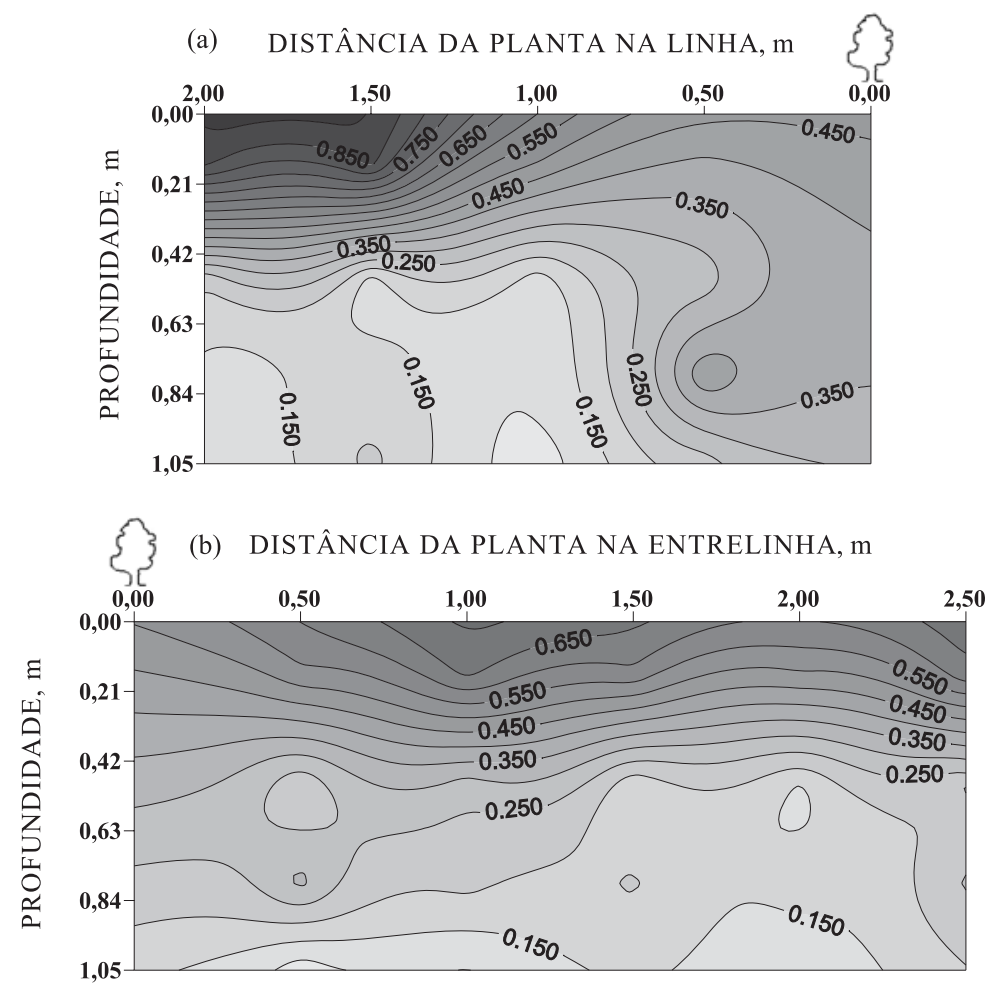

Figura 6. Distribuição espacial da densidade total de raízes da laranjeira 'Hamlin' enxertada em limoeiro 'Cravo", em cm de raízes por $\mathrm{cm}^{-3}$ de solo, no perfil de um Argissolo Acinzentado (PAC) não coeso, em uma toposseqüência de solos de tabuleiro localizada em Sapeaçu (BA), (a) na linha e (b) na entrelinha.

concentração de raízes, para que as plantas cítricas localizadas no solo PAC apresentassem crescimento estatisticamente superior ao daquelas localizadas no LAx e PAx (Paiva et al., 1998). As menores concentrações de raízes no PAC foram observadas a partir de 0,60 m de profundidade, tanto na linha como na entrelinha, sendo esses valores, como já abordado, aproximados daqueles observados nos horizontes superficiais dos solos LAx e PAx.

Os dados apresentados são muito importantes para orientar várias práticas de manejo, como localização de calcário e adubos, posicionamento de microaspersores ou gotejadores em pomares irrigados, capinas manuais ou mecanizadas para evitar o corte de raízes e outras.

\section{CONCLUSÕES}

1. As raízes de laranjeira 'Hamlin', enxertada em limoeiro 'Cravo", apresentaram grande sensibilidade à presença da coesão, com a densidade de raízes sendo 3,4 a 4,1 vezes maior no Argissolo Acinzentado (PAC), não coeso, em relação ao Latossolo Amarelo Argissólico (LAx) e Argissolo Amarelo (PAx), ambos coesos.

2. A profundidade efetiva do sistema radicular, até onde se encontraram $80 \%$ das raízes, foi maior no PAC, não coeso.
3. A distância efetiva do sistema radicular, até onde se encontraram $80 \%$ das raízes a partir do tronco, foi maior no PAx. Esse solo apresentou a menor profundidade efetiva das raízes.

4. Nos três solos, houve predominância de raízes com diâmetros $<1 \mathrm{~mm}$, seguidas daquelas com diâmetros entre 1 e $2 \mathrm{~mm}$ e $>2 \mathrm{~mm}$.

\section{LITERATURA CITADA}

BORDIN, I.; NEVES, C.S.V.J.; AINDA, F.T.; SOUZA, W.R.; DAVOGLIO JÚNIOR, A.C.; FURLANETO, T.L.R. \& TAVARES FILHO, J. Sistema radicular de plantas cítricas e atributos físicos do solo em um Latossolo argiloso submetido à escarificação. Ci. Rural, 35:820-825, 2005.

BRADY, N.C. Natureza e propriedades dos solos. 7.ed. Rio de Janeiro, Freitas Bastos, 1989. 878p.

CARTER, M.R. Quality, critical limits and standardization. In: LAL, R., ed. Encyclopedia of soil science. New York, Marcel Dekker, 2002. p.1062-1065.

CARVALHO, J.E.B.; SOUZA, L.S.; JORGE, L.A.C.; RAMOS, W.F.; COSTA NETO, A.O.; ARAÚJO, A.M.A.; LOPES, L.C. \& JESUS, M.S. Manejo de coberturas do solo e sua interferência no desenvolvimento do sistema radicular da laranja 'Pêra'. R. Bras. Frutic., 21:140-145, 1999. 
CASTLE, W.S.; TUCKER, D.P.H.; KREZDORN, A.H. \& YOUTSEY, C.O. Rootstocks for Florida citrus; rootstock selection, the first step to success. 2.ed. Gainesville, University of Florida, 1993. 92p.

CENTRO DE ESTATÍSTICA E INFORMAÇÕES - CEI. Informações básicas dos municípios baianos: Recôncavo Sul. Salvador, 1994. 761p.

CINTRA, F.L.D. \& LIBARDI, P.L. Caracterização física de uma classe de solo do ecossistema do Tabuleiro Costeiro. Sci. Agric., 55:367-378, 1998.

CINTRA, F.L.D.; LIBARDI, P.L. \& JORGE, L.A.C. Distribuição do sistema radicular de porta-enxertos de citros em ecossistema de Tabuleiro Costeiro. R. Bras. Frutic., 21:313317, 1999.

COElHo, E.F.; OLIVEIRA, F.C.; ARAÚJO, E.C.E. \& VASCONCELOS, L.F.L. Distribuição de raízes de laranja 'Pêra' sob sequeiro e irrigação por microaspersão em solo arenoso. Pesq. Agropec. Bras., 37:603-611, 2002.

DEMATTÊ; J.L.I.; MAZZA, J.A. \& DEMATTÊ, J.A.M. Caracterização e gênese de uma toposseqüência Latossolo Amarelo-Podzol originado de material da formação Barreiras - Estado de Alagoas. Sci. Agric., 53:20-30, 1996.

EMPRESA BRASILEIRA DE PESQUISA AGROPECUÁRIA . EMBRAPA. Centro Nacional de Pesquisa de Solos. Manual de métodos de análise de solo. 2.ed. Rio de Janeiro, 1997. $212 \mathrm{p}$

GUDDANTI, S. \& CHAMBERS, J.L. GSRoot automated root length measurement program, version 5.00; user's manual. Louisiana, Louisiana State University, 1993. 40p.

MACHADO, C.C. \& COELHO, R.D. Estudo da distribuição espacial do sistema radicular do limão 'Cravo' enxertado com lima ácida 'Tahiti'. Laranja, 21:359-380, 2000.

MAZZA, J.A.; VITTI, G.C.; PEREIRA, H.S.; MENEZES, G.M. \& TAGLIARINI, C.H. Influência da compactação no desenvolvimento do sistema radicular de citros: sugestão de método qualitativo de avaliação e recomendações de manejo. Laranja, 15:263-275, 1994.

MONTENEGRO, H.W.S. Contribuição ao estudo do sistema radicular das plantas cítricas. Piracicaba, Escola Superior de Agricultura Luiz de Queiroz, 1960. 143p. (Tese de Concurso para Professor Catedrático)

MOREIRA, C.S. Estudo da distribuição do sistema radicular da laranjeira 'Pêra' (Citrus sinensis, Osbeck) com diferentes manejos do solo. Piracicaba, Escola Superior de Agricultura Luiz de Queiroz, 1983. 97p. (Tese de LivreDocência)

NEVES, C.S.V.J.; DECHEN, A.R.; FELLER, C.; SAAB, O.J.G.A. \& PIEDADE, S.M.S. Efeito do manejo do solo no sistema radicular de tangerina 'Poncã' enxertada sobre limoeiro 'Cravo’ em Latossolo Roxo. R. Bras. Frutic., 20:246-253, 1998.
NEVES, C.S.V.J.; MURATA, I.M.; STENZEL, N.M.C.; MEDIDA, C.C.; BORGES, A.V.; OKUMOTO, S.H.; LEE, R.H.C. \& KANAI, H.T. Root distribution of rootstocks for 'Tahiti' lime. Sci. Agric., 61:94-99, 2004.

OLIVEIRA, L.B. Determinação da macro e microporosidade pela "mesa de tensão" em amostras de solo com estruturas indeformadas. Pesq. Agropec. Bras., 3:197-200, 1968.

OLIVEIRA, L.F.C.; VIEIRA, D.B. \& SOUZA, I.S. Estudo do sistema radicular da tangerineira 'Cleópatra' com copa de laranjeira 'Pêra'. Laranja, 19:117-131,1998.

PAIVA, A.Q. Dinâmica da água em uma toposseqüência de solos de tabuleiro do Estado da Bahia e sua implicação no crescimento da laranjeira. Viçosa, MG, Universidade Federal de Viçosa, 1997. 74p. (Tese de Mestrado)

PAIVA, A.Q.; SOUZA, L.S.; RIBEIRO, A.C. \& COSTA, L.M. Disponibilidade de água em uma toposseqüência de solos de tabuleiro do Estado da Bahia e sua relação com indicadores do crescimento da laranjeira. R. Bras.Ci. Solo, 22:367-377, 1998.

REZENDE, J.O.; MAGALHÃES, A.F.J.; SHIBATA, R.T.; ROCHA, E.S.; FERNANDES, J.C.; BRANDÃO, F.J.C. \& REZENDE, V.J.R.P. Citricultura nos solos coesos dos Tabuleiros Costeiros; análise e sugestões. Salvador, Secretaria da Agricultura, Irrigação e Reforma Agrária, 2002. 97p. (Série Estudos Agrícolas, 3)

SANTANA. M.B.; SOUZA, L.S.; SOUZA, L.D. \& FONTES, L.E.F. Atributos físicos do solo e distribuição do sistema radicular de citros como indicadores de horizontes coesos em dois solos de Tabuleiros Costeiros do Estado da Bahia. R. Bras. Ci. Solo, 30:1-12, 2006.

SANTOS, D.B.; COELHO, E.F. \& AZEVEDO, C.A.V. Absorção de água pelas raízes do limoeiro sob distintas freqüências de irrigação. R. Bras. Eng. Agríc. Amb., 9:327-333, 2005.

SOUZA, L.D.; CUNHA SOBRINHO, A.P.; RIBEIRO, L.S.; SOUZA, L.S. \& LEDO, C.A.S. Avaliação de plantas cítricas, em diferentes profundidades de plantio, em Latossolo Amarelo dos Tabuleiros Costeiros. R. Bras. Frutic., 26:241244, 2004a.

SOUZA, L.D.; RIBEIRO, L.S.; SOUZA, L.S.; LEDO, C.A.S. \& CUNHA SOBRINHO, A.P. Distribuição das raízes dos citros em função da profundidade da cova de plantio em Latossolo Amarelo dos Tabuleiros Costeiros. R. Bras. Frutic., 28:87-91, 2006.

SOUZA, L.D.; SOUZA, L.S. \& LEDO, C.A.S. Disponibilidade de água em pomar de citros submetido a poda e subsolagem em Latossolo Amarelo dos Tabuleiros Costeiros. R. Bras. Frutic., 26:69-73, 2004b.

SOUZA, L.S. Aspectos sobre o uso e manejo dos solos coesos dos Tabuleiros Costeiros. B. Inf. SBCS, 22:34-38, 1997. 